\title{
Amino acid metabolism as a therapeutic target in cancer: a review
}

\author{
Molly Endicott ${ }^{1} \mathbb{D} \cdot$ Michael Jones $^{1}(\mathbb{D}) \cdot$ Jonathon Hull $^{1} \mathbb{D}$
}

Received: 11 February 2021 / Accepted: 16 July 2021 / Published online: 22 July 2021

(c) The Author(s) 2021

\begin{abstract}
Malignant cells often demonstrate a proliferative advantage when compared to non-malignant cells. However, the rapid growth and metabolism required for survival can also highlight vulnerabilities specific to these malignant cells. One such vulnerability exhibited by cancer is an increased demand for amino acids (AAs), which often results in a dependency on exogenous sources of AAs or requires upregulation of de novo synthesis. These metabolic alterations can be exploited by therapy, which aims to improve treatment outcome and decrease relapse and reoccurrence. One clinically utilised strategy targeting AA dependency is the use of asparaginase in the treatment of acute lymphoblastic leukaemia (ALL), which results in a depletion of exogenous asparagine and subsequent cancer cell death. Examples of other successful strategies include the exploitation of arginine deiminase and methioninase, nutrient restriction of methionine and the inhibition of glutaminase. In this review, we summarise these treatment strategies into three promising avenues: AA restriction, enzymatic depletion and inhibition of metabolism. This review provides an insight into the complexity of metabolism in cancer, whilst highlighting these three current research avenues that have support in both preclinical and clinical settings.
\end{abstract}

Keywords Amino acids · Cancer $\cdot$ Oncology $\cdot$ Asparaginase $\cdot$ Metabolism

$\begin{array}{ll}\text { Abbreviations } \\ \text { AA } & \text { Amino acid } \\ \text { ALL } & \text { Acute lymphoblastic leukaemia } \\ \text { ALT } & \text { Alanine aminotransferase } \\ \text { AML } & \text { Acute myeloid leukaemia } \\ \text { BCAA } & \text { Branched chain amino acid } \\ \text { BCAT } & \text { Branched chain aminotransferase } \\ \text { NEAA } & \text { Non-essential amino acid } \\ \text { NSCLC } & \text { Non-small cell lung carcinoma } \\ \text { PDAC } & \text { Pancreatic ductal adenocarcinoma } \\ \text { PDOX } & \text { Patient-derived orthotopic xenograft } \\ \text { SCLC } & \text { Small-cell lung cancer }\end{array}$

Handling Editor: G. J. Peters.

Molly Endicott and Michael Jones have contributed equally to this work.

Jonathon Hull

jonathon2.hull@uwe.ac.uk

1 Faculty of Health and Life Sciences, University of the West of England, Coldharbour Lane, Bristol BS16 1QY, UK

\section{Introduction}

Cancer is a disease at the cellular level that results from oncogenic mutations that lead to altered cellular metabolism, promoting tumorigenesis (Pavlova and Thompson 2016). Malignant cells often demonstrate characteristic changes in their metabolism including increased rates of glutaminolysis and fatty acid synthesis, in addition to an increased uptake of glucose (Fadaka et al. 2017). These metabolic changes can expose vulnerabilities which are specific to malignant cells, such as an increased metabolic demand and inefficient adenosine triphosphate generation (Vettore et al. 2019). Literature is now highlighting the importance of AAs as metabolites and metabolic regulators in supporting oncogenesis, despite their primary role in protein synthesis (Ananieva and Wilkinson 2018; Li and Zhang 2016). Due to increased metabolic demands, an abundant supply of nutrients such as glucose and AAs are important for cancer cells to sustain their proliferative drive (Vettore et al. 2019). Therefore, nutrient deprivation strategies have been proposed as an alternative therapy for cancer treatment.

An increased rate of glycolysis, and therefore glucose consumption, is exhibited by many malignant cells and is referred to as the Warburg effect (Fig. 1; Warburg 1956), highlighting glucose consumption as a potential target for 


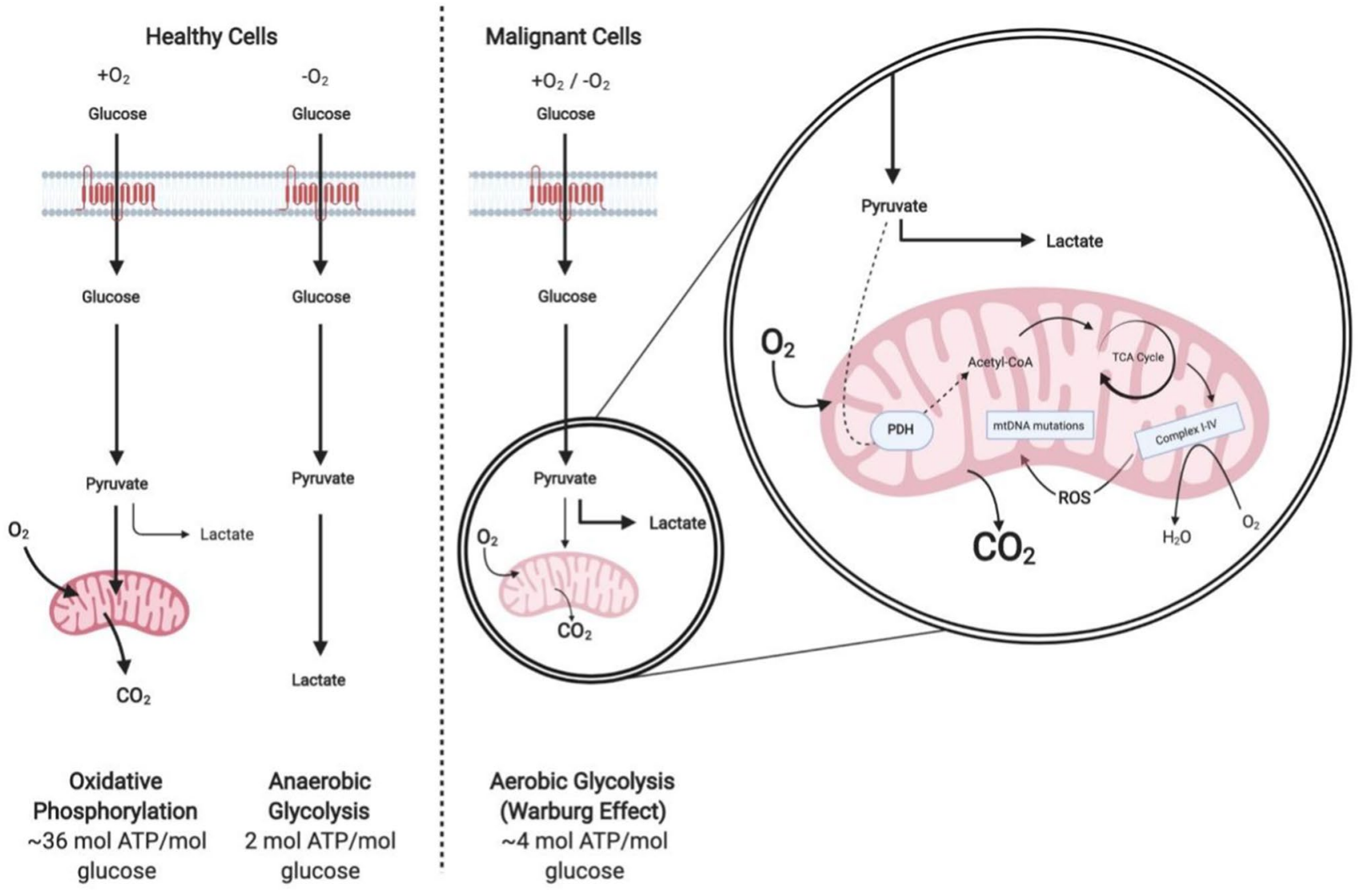

Fig. 1 A representation of the differences between oxidative phosphorylation, anaerobic glycolysis and aerobic glycolysis (Warburg effect). In the presence of oxygen, healthy cells metabolise glucose to pyruvate via glycolysis. Pyruvate is oxidised within the mitochondria to produce $\mathrm{CO}_{2}$ during oxidative phosphorylation. In the absence of oxygen, cells generate lactate from pyruvate. This allows glycolysis to continue with reduced ATP production in comparison to oxidative phosphorylation. Alternatively, malignant cells undergo aerobic

therapeutic intervention. However, glucose restriction leads to systemic toxicity due to the effects of deprivation on nonmalignant cells (Jeon et al. 2016). Unlike glucose, the ability to synthesise non-essential amino acids (NEAAs) de novo is commonly maintained in non-malignant cells yet is lost in malignancy. This ensures non-malignant cells are unaffected by specific AA restrictions, resulting in the emergence of AA restriction as a viable therapeutic strategy. Like glucose, there are major differences in the uptake and metabolism of several AAs in malignant versus non-malignant cells (Jain et al. 2012). It is believed that AAs, rather than glucose, account for the majority of the carbon biomass in proliferating cells, highlighting a significant demand for AAs (Hosios et al. 2016).

Amino acid restriction has already proven to be clinically effective in the treatment of ALL, with the use of asparaginase. Asparaginase is a bacterial derived enzyme that depletes serum levels of the NEAA, asparagine. glycolysis regardless of oxygen status. Whilst mitochondria remain functional, minimal oxidative phosphorylation can take place. Abbreviations: ATP adenosine triphosphate; Complex I-IV mitochondrial respiratory chain complexes I-IV; $m t D N A$ mitochondrial DNA; $P D H$ pyruvate dehydrogenase; $R O S$ reactive oxygen species; TCA tricarboxylic acid. Adapted in Biorender from Vander Heiden et al. (2009); Kim and Dang (2006)

Asparaginase represents one of the first examples of a therapeutic approach targeting AA metabolism by exploiting AA auxotrophy in cancer, and has resulted in notable improvement of paediatric ALL outcomes. Asparaginase treatment is one of the most successful metabolism-targeting therapies to date, and its success has prompted further studies looking into the effects of exploiting AA metabolism in malignant cells (Vettore et al. 2019). A number of strategies have been proposed to exploit AA metabolism and the increased demand for nutrients in malignant cells. These strategies include dietary restriction of AAs, enzymatic depletion of exogenous AAs and inhibition of enzymatic AA metabolism. All of these methods highlight specific vulnerabilities and potential avenues for cancer therapy. This review will summarise key studies relating to the targeting of AA metabolism in cancer therapy; including ALL, melanoma and hepatocellular carcinoma (Table 1). 
Table 1 Summary of key evidence identified in this review

\begin{tabular}{|c|c|c|c|}
\hline Treatment mechanism & Model type & Preclinical/clinical evidence & References \\
\hline \multicolumn{4}{|l|}{ Enzymatic depletion } \\
\hline Asparaginase & Clinical use in ALL & $\begin{array}{l}\text { Mortality rates in patients aged } \\
0-24 \text { years have progressively } \\
\text { decreased by } 82 \% \text { from } 1971 \text { to } 2016 \\
\text { since the introduction of asparaginase }\end{array}$ & Cancer Research UK (2018) \\
\hline Arginine deiminase & $\begin{array}{l}\text { Human metastatic melanoma clinical } \\
\text { trials }\end{array}$ & $\begin{array}{l}\text { Phase } 2 \text { clinical trials predicted an } \\
\text { increase in median survival of } \\
8 \text { months ( } 7 \text { vs } 15 \text { months) in stage IV } \\
\text { metastatic melanoma patients }\end{array}$ & Ascierto et al. (2005) \\
\hline Recombinant methioninase & $\begin{array}{l}\text { Pancreatic cancer and melanoma } \\
\text { patient-derived orthotopic xenograft } \\
\text { nude-mouse models }\end{array}$ & $\begin{array}{l}\text { When treated with methioninase, mice } \\
\text { demonstrated a reduced tumour } \\
\text { volume in both pancreatic ( } 694 \text { vs } 201 \\
\mathrm{~mm}^{2} \text { ) and melanoma ( } 3755 \text { vs } 858 \\
\mathrm{~mm}^{2} \text { ) cancer models }\end{array}$ & Kawaguchi et al. (2018) \\
\hline \multicolumn{4}{|l|}{ Nutritional restriction } \\
\hline Branched chain amino acids & Clinical use in MSUD & $\begin{array}{l}\text { Potential activity against cancers that } \\
\text { are dependent on BCAAs, yet evi- } \\
\text { dence of its efficacy is lacking }\end{array}$ & N/A \\
\hline Methionine & $\begin{array}{l}\text { Azoxymethane-induced colon carcino- } \\
\text { genesis male F344 rat model }\end{array}$ & $\begin{array}{l}\text { A methionine restricted diet resulted in } \\
\text { a reduction of colonic cell prolifera- } \\
\text { tion by } 12 \% \text { compared to controls and } \\
\text { reduced preneoplastic aberrant crypt } \\
\text { foci }\end{array}$ & Komninou et al. (2006) \\
\hline Ketogenic diet & $\begin{array}{l}\text { Luciferase-tagged VM-M3 mouse mod- } \\
\text { els of metastatic cancer }\end{array}$ & $\begin{array}{l}\text { The ketogenic diet was associated with a } \\
\text { reduced tumour growth and increased } \\
\text { mean survival ( } 31.2 \text { vs } 48.9 \text { days) }\end{array}$ & Poff et al. (2013) \\
\hline \multicolumn{4}{|l|}{ Enzymatic inhibition } \\
\hline Alanine aminotransferase 2 & $\begin{array}{l}\text { ALT2 knockdown in human NSCLC } \\
\text { cell lines }\end{array}$ & $\begin{array}{l}\text { Approximately a } 40 \% \text { reduction in rela- } \\
\text { tive cell density in ALT2 knockdown } \\
\text { NSCLC cells compared to wildtype }\end{array}$ & Hodakoski et al. (2019) \\
\hline Gabapentin & Human glioma cell lines & $\begin{array}{l}\text { Approximately, a } 56 \% \text { concentration- } \\
\text { dependent reduction in glioma prolif- } \\
\text { eration when treated with gabapentin }\end{array}$ & Tönjes et al. (2013) \\
\hline CB-839 (Telaglenastat) & $\begin{array}{l}\text { Human advanced or metastatic renal cell } \\
\text { carcinoma clinical trials }\end{array}$ & $\begin{array}{l}\text { A phase } 2 \text { clinical trial demonstrated } \\
\text { an increase in median progression } \\
\text { free survival of } 1.9 \text { months ( } 3.8 \\
\text { vs } 1.9 \text { months) when treated with } \\
\text { everolimus and CB- } 839 \text { compared to } \\
\text { the control }\end{array}$ & Motzer et al. (2019) \\
\hline
\end{tabular}

The table contains key treatment mechanisms defined into the three potential avenues of targeting AA metabolism for cancer treatment; enzymatic depletion, nutritional restriction and enzymatic inhibition. The table details both preclinical and clinical evidence in addition to the experimental model type used, whilst summarising the key data in support of targeting AA metabolism in cancer

$A A$ amino acid; $A L L$ acute lymphoblastic leukaemia; $A L T$ alanine aminotransferase; BCAAs branched chain amino acids; $M S U D$ maple syrup urine disease; NSCLC non-small cell lung carcinoma

\section{Enzymatic depletion of amino acids}

Treatment consisting of AA metabolising enzymes has clinically demonstrated anti-proliferative efficacy against cancer, notably ALL. Non-malignant cells have an innate ability to synthesise NEAAs, yet malignant cells often have underlying genetic mutations that result in a loss of this ability. This results in many cancers becoming auxotrophic for certain NEAAs and therefore tumours must rely on exogenous sources of these AAs for growth and survival (Vettore et al.
2019). In the example of ALL, one of the hallmarks of the disease is a lymphoblast deficiency in asparagine synthetase. High rates of protein synthesis and a poor ability to synthesise asparagine drives ALL lymphoblasts into becoming dependent on the extracellular availability of asparagine (Chiu et al. 2019).

Administration of asparaginase catalyses the hydrolysis of asparagine in the serum to aspartate and ammonia, resulting in decreased serum asparagine levels and growth inhibition or death of leukemic cells (Cachumba et al. 2016). 
The ability of non-malignant cells to continue to synthesise asparagine allows the resulting low levels of serum asparagine to disrupt leukemic cell viability without disturbing non-malignant cells (Ali et al. 2016). Since the introduction of asparaginase in the 1960s for the treatment of ALL, mortality rates in patients aged 0-24 years has progressively decreased by $82 \%$ between 1971 and 2016 (Cancer Research UK 2018). The success of asparaginase therapy has prompted the development of additional therapeutics designed to exploit cancer AA dependencies. These metabolic dependencies are described in many cancers, with common deficiencies observed in argininosuccinate synthetase (Patil et al. 2016), and glutamine synthetase (Bolzoni et al. 2016; Chiu et al. 2019; Furusawa et al. 2018).

Arginine auxotrophy has been successfully exploited utilising the microbial derived enzyme, arginine deiminase, which catalyses the conversion of arginine to its precursor citrulline. Clinical trials of arginine deiminase in humans have demonstrated efficacy in both hepatocellular carcinomas and melanomas (Ascierto et al. 2005; Glazer et al. 2010). Initial studies demonstrated a significant reduction in serum arginine levels following arginine deiminase treatment, associated with an increased median survival of 8 months in metastatic melanoma patients compared to controls (Ascierto et al. 2005). Comparatively, advanced hepatocellular carcinoma patients exhibited an overall median survival of 11.4 months (vs 10.7 months), demonstrating an increased efficacy compared to the first-line treatment, sorafenib (Glazer et al. 2010; Llovet et al. 2008).

Recently, arginine deiminase has demonstrated efficacy in a number of alternative cancers including small-cell lung cancer (SCLC) and acute myeloid leukaemia (AML). Kelly et al. (2012) demonstrated that SCLC cells frequently lack expression of argininosuccinate synthetase and treatment with arginine deiminase induced metabolic stress and subsequent autophagy, which progressed to apoptosis in up to $16 \%$ of cancer cells. In addition, arginine deiminase treatment in SCLC xenograft mouse models induced a significant dosedependent reduction in tumour growth compared to controls. Miraki-Moud et al. (2015) demonstrated similar results in AML cells in vivo, finding that arginine deprivation induced by arginine deiminase significantly reduced the percentage of AML cells by more than $50 \%$ in the bone marrow of mouse models. Utilising the same models, arginine deiminase in combination with the chemotherapeutic agent cytarabine (commonly used to treat AML) demonstrated improved efficacy than cytarabine alone (Miraki-Moud et al. 2015).

Another example supported by recent evidence is the enzymatic depletion of the essential AA, methionine. Cancer cell proliferation appears dependent on exogenous methionine and is known as methionine dependence or the Hoffman effect (Hoffman 2015; Kaiser 2020). Hoffman and Erbe (1976) demonstrated that malignant cells were able to synthesise high levels of methionine endogenously, yet still insufficient levels to maintain cancer growth. Stern and Hoffman (1984) noted that an overall increase in transmethylation reactions within malignant cells is likely the basis of this methionine-dependence. This alteration within malignant cells has resulted in methionine addiction being recognised as a fundamental hallmark of cancer and oncogenic transformation (Booher et al. 2012; Chello and Bertino 1973; Coalson et al. 1982; Halpern et al. 1974; Hoffman 2015; Hoffman and Erbe 1976; Hoffman and Jacobsen 1980; Hoffman et al. 1979; Mecham et al. 1983; Stern et al.1984; Yamamoto et al. 2020).

First reported in 1973, methioninase was initially isolated from Clostridium sporogenes and successfully inhibited the growth of Walker carcinosarcoma 256 implanted in male Wistar rats (Kreis and Hession 1973). Recently, with the use of patient-derived orthotopic xenograft (PDOX) mouse models of cancer, Kawaguchi et al. (2018) demonstrated that pancreatic cancer and melanoma exhibited methionine dependency. It was demonstrated that mice treated with recombinant methioninase exhibited a reduced tumour volume in both pancreatic (694 vs $201 \mathrm{~mm}^{2}$ ) and melanoma (3755 vs $858 \mathrm{~mm}^{2}$ ) cancer models (Kawaguchi et al. 2018). This work proposed that the recombinant methioninase decreased serum methionine levels, which in turn resulted in an inadequate methionine supply to the tumours, leading to a reduction in tumour volume.

Following the success of methioninase in preclinical models, studies have highlighted the potential of both intravenous and oral recombinant methioninase in human clinical trials. In a phase 1 clinical trial assessing metastatic breast cancer patients, plasma methionine levels decreased significantly when administered with 20,000 units of recombinant methioninase (Tan et al. 1996). However, this trial did not assess anti-tumour activity. More recently, Han et al. (2020) investigated the use of oral recombinant methioninase as a supplement in advanced cancers. This study demonstrated an approximate $70 \%$ decrease in prostate-specific antigen in a patient with bone-metastatic prostate cancer following a twice daily dose of 250 units of methioninase over a 3-month period. Furthermore, the patient's haemoglobin increased from 7.4 to $8.7 \mathrm{~g} / \mathrm{dl}$ during the trial, suggesting increased bone functionality following treatment. Whilst the Han et al. (2020) study has demonstrated a potentially safe and effective treatment to reduce circulating methionine, double blind clinical trials are needed to assess efficacy regarding patient survival.

Taken together, the data from these studies supports the enzymatic depletion of AAs as a successful cancer therapy. Although this review focusses on the enzymes with the widest clinical support, there are whole families of enzymes that have yet to be explored. However, whilst there is promise in these therapies many patients experience a hypersensitivity 
reaction to the infused protein which limits the treatments use (Battistel et al. 2020; Zarei et al. 2019), highlighting a need for orally available treatments (Han et al. 2020). This also leaves opportunities for other mechanisms of AA depletion, such as dietary restriction. The dietary restriction of phenylalanine and branched chain amino acids (BCAAs) are already performed in the clinical setting of phenylketonuria and maple syrup urine disease, respectively (Blackburn et al. 2017).

\section{Nutritional restriction of amino acids}

Otto Warburg first noted changes in the metabolism of glucose within malignant cells in order to support rapid cell proliferation, growth and survival (Warburg 1956). Regardless of oxygen status, malignant cells often produce energy by glycolysis followed by lactic acid fermentation (Fig. 1; $\mathrm{Li}$ et al. 2015). This altered metabolism has been exploited clinically through the use of fluorodeoxyglucose positron emission tomography, enabling the detection of malignant tumours (Hsu and Sabatini 2008). Due to the high rate of glucose consumption by malignant cells, glucose deprivation is an attractive therapeutic avenue in many cancers. Numerous studies have demonstrated significantly lower glucose concentrations in malignant cells compared to corresponding non-malignant tissues (Rocha et al. 2015; Urasaki et al. 2012; Ziebart et al. 2011), with average reductions of up to $46 \%$ reported in lung tumours (Rocha et al. 2015).

Malignant cells can even adapt to glucose poor conditions by adopting alternative metabolic pathways to support growth. It has been demonstrated in conditions of glucose deprivation, malignant cells can synthesise glucose de novo from non-carbohydrate sources (gluconeogenesis) (Grasmann et al. 2019). Hodakoski et al. (2019) identified that the catabolism of alanine by alanine aminotransferase 2 (ALT2) to pyruvate, was critical for the survival of nonsmall cell lung carcinoma (NSCLC) cells during glucose starvation. After knockdown of ALT2, cells were significantly more sensitive to glucose withdrawal compared to wildtype cells, which were rescued when supplemented with pyruvate. Increased ALT2 expression has also been reported in human breast cancer and demonstrated a positive correlation with tumour grade and proliferation (Cao et al. 2017). This research highlights the significant role of glucogenic AAs to feed gluconeogenesis in glucose deprived environments (Cao et al. 2017; Hodakoski et al. 2019). However, as 19 out of 22 AAs are considered glucogenic, restriction does not seem practical in a clinical setting.

A common example of dietary cancer therapy is the ketogenic diet, providing a fat-rich, low carbohydrate diet. The rationale is to reduce circulating glucose levels and induce ketosis. This promotes energy starvation in malignant cells that are unable to utilise ketone bodies, whilst non-malignant cells adapt (Klement 2017; Weber et al. 2018). The ketogenic diet has been demonstrated to decrease cancer progression within mouse models of metastatic cancer, slowing tumour growth and increasing mean survival by $56.7 \%$ (31.2 vs 48.9 days) (Poff et al. 2013). Zhou et al. (2007) compared a standard diet to a ketogenic diet where the major difference between these diets was the ketogenic ratio of 4:1 (fat: carbohydrate and protein) when following the ketogenic diet. Intracerebral tumour growth of both the CT-2A and U87-MG tumours were reduced by approximately $65 \%$ and $35 \%$, respectively. This was associated with improved survival in the ketogenic diet group when compared to control mice. Further to these studies, Rieger et al. (2014) used mouse models to observe the effects of a ketogenic diet in combination with bevacizumab, a drug designed to block vascular endothelial growth factor (Byrne et al. 2005). The combination of both bevacizumab and a ketogenic diet resulted in a $42 \%$ reduction in tumour volume when compared to mice receiving bevacizumab alone $\left(13.8 \mathrm{~mm}^{3}\right.$ vs $\left.23.9 \mathrm{~mm}^{3}\right)$, which was reflected in an increased survival. Despite the promising preclinical data, human studies have not shown consistent clinical improvement. However, many human studies are limited by factors including low patient numbers, poor adherence, lack of randomisation and the absence of a control group. These factors are controlled in preclinical studies utilising animal models, which may be the reason that preclinical success was not replicated in the human trials.

Increasing evidence has highlighted that BCAAs, leucine, isoleucine and valine, are required for malignant growth and act as a source of energy in many cancers (Ananieva and Wilkinson 2018). Recent evidence has demonstrated that the key enzymes in BCAA metabolism: the branched chain aminotransferase (BCAT) and the branched chain keto acid dehydrogenase complex are overexpressed in many cancers and correlate with poorer survival, chemotherapeutic resistance, and enhanced cancer cell proliferation, migration and invasion (Conway et al. 2016; Hattori et al. 2017; Mayers et al. 2016; Tönjes et al. 2013; Zheng et al. 2016). Increased expression of BCAT and increased BCAA uptake was observed in mouse NSCLC tumours, in which leucine uptake was over threefold higher than control lung tissue. In NSCLC tumours, leucine uptake contributed to DNA and NEAA synthesis, important for tumour growth, while pancreatic ductal adenocarcinoma (PDAC) tumours demonstrated decreased BCAA uptake and little utilisation (Mayers et al. 2016). In contrast, Dey et al. (2017) demonstrated that BCAT2 overexpression in PDAC cells positively correlated with the aggressive growth in PDAC tumours driven by chr18q21 chromosomal deletion, suggesting (conversely) PDAC tumours are dependent on BCAAs. 
It is apparent that BCAA metabolism in cancer is complex. The long-term dietary restriction of all 3 BCAAs is required for maple syrup urine disease treatment and has demonstrated a successful clinical outcome for an otherwise fatal disease (Blackburn et al. 2017). Utilising dietary BCAA restriction in cancer therapy could inhibit the varying carcinogenic pathways that require BCAAs or its metabolites. However, current clinical data assessing dietary interventions targeting cancer are lacking, despite promising preclinical data. For example, Komninou et al. (2006) assessed the dietary restriction of methionine on an azoxymethaneinduced colon carcinogenesis rat model. The formation of preneoplastic aberrant crypt foci in the colon was reduced in rats fed on a methionine restricted diet, with a $12 \%$ reduction in colonic cell proliferation compared to controls. However, dietary restriction is often complicated due to the complex AA content of food. The isolation of a single AA whilst maintaining a varied and nutritious diet is difficult but is possible when following a diet of medical origin. However, it may be more clinically manageable to instead target the metabolism of specific AAs, rather than restricting them.

\section{Enzymatic inhibition of amino acid metabolism}

A number of pharmacological inhibitors have been extensively researched to inhibit the function of key enzymes involved in AA metabolism, thus disrupting cancer progression. The BCAT enzyme has been identified in having a central role in the pathogenesis of a number of cancers (Hattori et al. 2017; Mayers et al. 2016; Tönjes et al. 2013), with knockdown of the BCAT gene demonstrating reduced proliferation of cancer cells both in vitro and in vivo (Hattori et al. 2017; Tönjes et al. 2013). The medication gabapentin, originally designed as a gamma-aminobutyric acid-mimetic, has demonstrated both anticonvulsive and analgesic effects. Although the mechanism of gabapentin remains unclear, its main molecular target involves the inhibition of voltagegated calcium channels at dorsal root ganglion neurons, which contributes to its pain attenuating effects (Kukkar et al. 2013). However, evidence has described gabapentin as an inhibitor of BCAT1. Structural analysis has demonstrated gabapentin acts as an analogue of leucine and can competitively inhibit the transaminase activity of BCAT1 (Goto et al. 2005). In vitro studies have demonstrated that inhibition of BCAT1 by gabapentin dose-dependently disrupts clonogenic growth in chronic myeloid leukaemic cells and promotes intracellular BCAA accumulation (Hattori et al. 2017). Supporting this, following treatment with gabapentin levels of valine, leucine and isoleucine increased by factors of 1.83, 2.18 and 2.32, respectively, in gliomas that harbour wildtype isocitrate dehydrogenase 1 (Tönjes et al. 2013).
This reduced BCAT activity was associated with reduced glutamate release and led to reduced proliferation and invasiveness in vitro (Tönjes et al. 2013).

Not all studies have confirmed that the anti-proliferative effects of gabapentin on tumour cells are dependent of BCAT1 inhibition. Grankvist et al. (2018) demonstrated that at $10 \mathrm{mM}$, gabapentin significantly reduced the growth of colon cancer cells by approximately $50 \%$ at $96 \mathrm{~h}$, despite little BCAT1 expression and BCAT2 as the major isoform. Additionally, the cells were supplemented with branched chain keto acids which failed to recover cell growth in the presence of gabapentin, demonstrating that inhibition of cancer cell growth was not due to inhibition of BCAT2. The mechanism by which gabapentin suppresses cancer cell growth in these cells remains unclear. However, the diverse anti-cancer activity of gabapentin highlights it as a candidate for treatment against cancers with different metabolic phenotypes. For example, malignancies that lack BCAT activity and have little dependency on BCAAs or those that rely on BCAT2 activity rather than BCAT1 (Dey et al. 2017; Grankvist et al. 2018; Mayers et al. 2016).

In the 1950 s, a dependence on an abundant supply of exogenous glutamine was noted in mammalian cell lines (Eagle 1955). Glutamine metabolism contributes to a number of diverse roles which support the ability of malignant cells to meet increased energy demands and continuously grow. This includes energy generation, cell proliferation, maintaining redox homeostasis and the synthesis of NEAAs, fatty acids and nucleotides (Fig. 2; Martinez-Outschoorn et al. 2017). However, recent studies have demonstrated that glutamine requirements are heterogeneous amongst different cell lines and that the tissue of origin, genetics and the tumour microenvironment all impact the utilisation of glutamine within the cancer cell (Cluntun et al. 2017). As a NEAA, glutamine is synthesised de novo by the enzyme glutamine synthetase (Tardito et al. 2015). However, some malignancies rely on an exogenous supply of glutamine due to a low expression of glutamine synthetase (Cluntun et al. 2017). Therefore, in the absence or inhibition of glutaminase, malignancies which rely on energy from an exogenous supply of glutamine will be unable to utilise nutrients from this source.

There are a number of approaches to target glutamine metabolism including blocking cellular uptake of glutamine, depletion of glutamine in the blood and inhibition of enzymes involved in glutamine synthesis and catabolism, all of which provide potential avenues for cancer therapy (Lukey et al. 2013; Martinez-Outschoorn et al. 2017). Targeting glutaminase function utilising small molecules or gene knockdown approaches has produced promising preclinical results in many malignancies such as NSCLC and B cell lymphoma (Le et al. 2012; Van den Heuvel et al. 2012). Glutaminase inhibitors have demonstrated success in both 


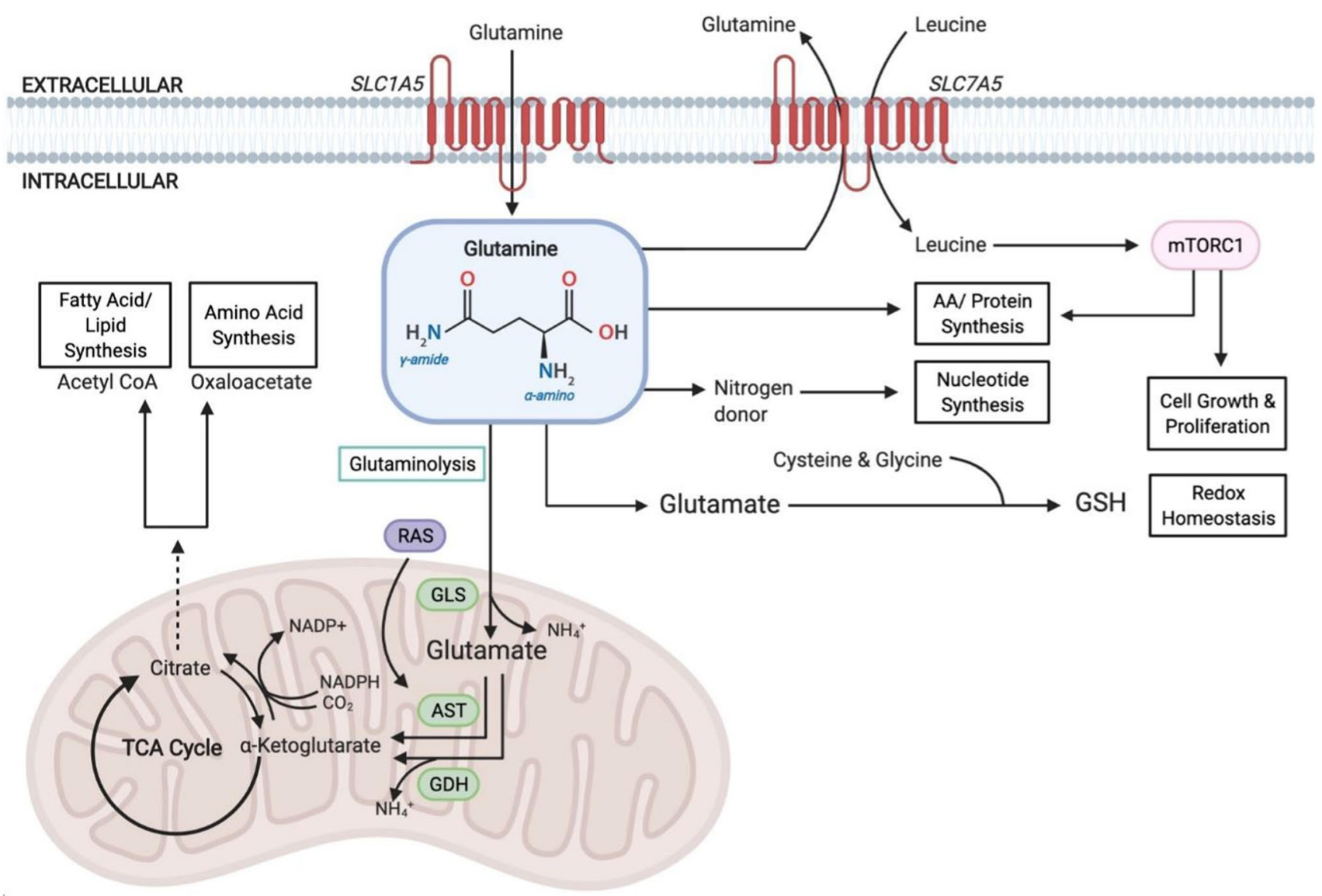

Fig. 2 The role of glutamine in cancer. Glutamine enables rapidly proliferating cells to meet increased energy demands in addition to its utilisation in protein synthesis. Glutamine enters the cell via the amino acid transporter SLC1A5 and is converted to glutamate in the mitochondria via a deamination reaction catalysed by GLS. Glutamate is further converted to the TCA cycle intermediate $\alpha$-ketoglutarate. $\alpha$-ketoglutarate is a critical metabolite involved in both ATP production and replenishing TCA cycle intermediates (anaplerosis). Cytosolic glutamate is critical for maintaining redox homeostasis through the production of GSH which protects against oxida-

preclinical and clinical studies. Telaglenastat (CB-839) is a potent and selective inhibitor of both splice variants of glutaminase, which has exhibited antiproliferative effects on triple negative breast cancer cell lines and xenograft models (Gross et al. 2014). In a patient-derived triple negative breast cancer xenograft, Gross et al. (2014) demonstrated a $61 \%$ inhibition of tumour growth with telaglenastat treatment alone. Furthermore, treatment with a combination of telaglenastat and paclitaxel demonstrated a $100 \%$ tumour inhibition relative to controls.

Phase 1 clinical trials have demonstrated the success of telaglenastat as a well-tolerated monotherapy in patients with multiple myeloma and lymphoma through the successful inhibition of glutaminase in tumours (Vogl et al. 2015). Vogl et al. (2015) also highlighted the success of tive stress. Glutamine efflux via the SLC7A5 amino acid transporter allows leucine to enter the cell and activate mTORC1-mediated cell growth. Abbreviations: AST aspartate transaminase; ATP adenosine triphosphate; $G D H$ glutamate dehydrogenase; $G L S$ glutaminase; $G S H$ S-glutathione; mTORC1 mammalian target of rapamycin complex 1; $N A D P \pm$ nicotinamide adenine dinucleotide phosphate; $R A S$ rat sarcoma GTPase; SLC1A5 solute carrier family 1 member 5; SLC7A5 solute carrier family 7 member 5; TCA tricarboxylic acid. Adapted in Biorender from Choi and Park (2018); Hensley et al. (2013); Martinez-Outschoorn et al. (2017)

telaglenastat in combination with pomalidomide/ dexamethasone, supporting the clinical use of telaglenastat for relapsed multiple myeloma. Further phase 1 studies also demonstrated the success of telaglenastat as a monotherapy in addition to studying combinations with other drugs such as everolimus in patients with renal cell carcinoma (MericBernstam et al. 2016). As a result of the success demonstrated in phase 1 clinical trials, the work has progressed into phase 2 with one active phase 2 trial comparing telaglenastat in combination with everolimus to a placebo with everolimus in advanced or metastatic renal cell carcinoma. The randomised, double-blind, placebo-controlled phase 2 trial is approaching completion (National Institute of Health 2017). However, initial results from the trial are promising, with a median progression-free survival of 3.8 months when 
patients were treated with telaglenastat and everolimus, compared to 1.9 months for those who received the placebo and everolimus (Motzer et al. 2019). This promising initial data, along with the progression of other studies to phase 2 clinical trials, provides support for the use of telaglenastat as a successful glutaminase inhibitor.

\section{Conclusion}

The extensive mutational heterogeneity of cancer highlights a growing need for personalised medicine. Therapies currently exist to target the many pathways associated with tumour progression. Yet many patients suffer due to the toxicity of these treatments, in addition to cancer cell adaptations which results in chemoresistance. Research needs to identify novel therapeutic avenues to tackle the resistant forms of these cancers or provide a less aggressive alternative to current therapies in patients not deemed fit to treat. Amino acids are required for a number of vital processes and many malignant cells exhibit genetic abnormalities that compromise their ability to obtain or utilise an adequate supply of the AAs required for tumorigenesis. Nutrient restriction, enzymatic depletion and enzymatic inhibition of AA metabolism have all demonstrated success in preclinical and clinical models, supporting these therapies as viable strategies for cancer treatment (Table 1). These alternative approaches have the potential to revolutionise standard clinical practice and could transform relapse and reoccurrence statistics for many cancers. However, initial promising results need to be supported by double-blind clinical trials. The research summarised in this review promises success in the underlying principle of AA restriction as an effective non-genotoxic therapy, that can be utilised as both a monotherapy or combination therapy.

Acknowledgements The authors would like to thank Professor Myra Conway and Dr Tim Craig for reviewing the manuscript prior to submission. Figures were created with BioRender.

Author contributions All authors contributed to the review conception and design. Material review and draft preparation were performed by Michael Jones and Molly Endicott. Review and editing was performed by Jonathon Hull. All authors read and approved the final manuscript.

Funding Not applicable.

Data availability Not applicable.

Code availability Not applicable.

\section{Declarations}

Conflict of interest The authors declare that they have no conflict of interest.
Ethical approval Not applicable.

Consent to participate Not applicable.

Consent for publication Not applicable.

Open Access This article is licensed under a Creative Commons Attribution 4.0 International License, which permits use, sharing, adaptation, distribution and reproduction in any medium or format, as long as you give appropriate credit to the original author(s) and the source, provide a link to the Creative Commons licence, and indicate if changes were made. The images or other third party material in this article are included in the article's Creative Commons licence, unless indicated otherwise in a credit line to the material. If material is not included in the article's Creative Commons licence and your intended use is not permitted by statutory regulation or exceeds the permitted use, you will need to obtain permission directly from the copyright holder. To view a copy of this licence, visit http://creativecommons.org/licenses/by/4.0/.

\section{References}

Ali U, Naveed M, Ullah A, Ali K, Shah SA, Fahad S, Mumtaz AS (2016) L-asparaginase as a critical component to combat acute lymphoblastic leukaemia (ALL): a novel approach to target ALL. Eur J Pharmacol 771:199-210. https://doi.org/10.1016/j.ejphar. 2015.12.023

Ananieva EA, Wilkinson AC (2018) Branched-chain amino acid metabolism in cancer. Curr Opin Clin Nutr Metab Care 21(1):64. https://doi.org/10.1097/MCO.0000000000000430

Ascierto PA, Scala S, Castello G, Daponte A, Simeone E, Ottaiano A, Beneduce G, De Rosa V, Izzo F, Melucci MT, Ensor CM (2005) Pegylated arginine deiminase treatment of patients with metastatic melanoma: results from phase I and II studies. J Clin Oncol 23(30):7660-7668. https://doi.org/10.1200/JCO.2005.02.0933

Battistel AP, da Rocha BS, dos Santos MT, Daudt LE, Michalowski MB (2020) Allergic reactions to asparaginase: retrospective cohort study in pediatric patients with acute lymphoid leukemia. Hematol Transfus Cell Ther. https://doi.org/10.1016/j.htct.2019. 10.007

Blackburn PR, Gass JM, e Vairo FP, Farnham KM, Atwal HK, Macklin S, Klee EW, Atwal PS (2017) Maple syrup urine disease: mechanisms and management. Appl Clin Genet 10:57-66. https://doi. org/10.2147/TACG.S125962

Bolzoni M, Chiu M, Accardi F, Vescovini R, Airoldi I, Storti P, Todoerti K, Agnelli L, Missale G, Andreoli R, Bianchi MG (2016) Dependence on glutamine uptake and glutamine addiction characterize myeloma cells: a new attractive target. Blood 128(5):667679. https://doi.org/10.1182/blood-2016-01-690743

Booher K, Lin DW, Borrego SL, Kaiser P (2012) Downregulation of Cdc6 and pre-replication complexes in response to methionine stress in breast cancer cells. Cell Cycle 11(23):4414-4423. https:// doi.org/10.4161/cc.22767

Byrne AM, Bouchier-Hayes DJ, Harmey JH (2005) Angiogenic and cell survival functions of vascular endothelial growth factor (VEGF). J Cell Mol Med 9(4):777-794. https://doi.org/10.1111/j. 1582-4934.2005.tb00379.x

Cachumba JJM, Antunes FAF, Peres GFD, Brumano LP, Dos Santos JC, Da Silva SS (2016) Current applications and different approaches for microbial L-asparaginase production. Braz $\mathrm{J}$ Microbiol 47:77-85. https://doi.org/10.1016/j.bjm.2016.10.004 
Cancer Research UK (2018) Mortality statistics. Available from: https://www.cancerresearchuk.org/health-professional/cancerstatistics/statistics-by-cancer-type Accessed 18 September 2020

Cao Y, Lin SH, Wang Y, Chin YE, Kang L, Mi J (2017) Glutamic pyruvate transaminase GPT2 promotes tumorigenesis of breast cancer cells by activating sonic hedgehog signaling. Theranostics 7(12):3021-3033. https://doi.org/10.7150/thno.18992

Chello, Paul L., Joseph R. Bertino. (1973). Dependence of 5-methyltetrahydrofolate utilization by L5178Y murine leukemia cells in vitro on the presence of hydroxycobalamin and transcobalamin II. Cancer Research 33(8):1898-1904. https://cancerres.aacrj ournals.org/content/33/8/1898.short

Chiu M, Taurino G, Bianchi MG, Kilberg MS, Bussolati O (2019) Asparagine synthetase in cancer: beyond acute lymphoblastic leukemia. Front Oncol 9:1480. https://doi.org/10.3389/fonc.2019. 01480

Choi YK, Park KG (2018) Targeting glutamine metabolism for cancer treatment. Biomol Ther 26(1):19-28. https://doi.org/10. 4062/biomolther.2017.178

Cluntun AA, Lukey MJ, Cerione RA, Locasale JW (2017) Glutamine metabolism in cancer: understanding the heterogeneity. Trends Cancer 3(3):169-180. https://doi.org/10.1016/j.trecan.2017.01. 005

Coalson DW, Mecham JO, Stern PH, Hoffman RM (1982) Reduced availability of endogenously synthesized methionine for S-adenosylmethionine formation in methionine-dependent cancer cells. Proc Natl Acad Sci 79(14):4248-4251. https://doi.org/10.1073/ pnas.79.14.4248

Conway ME, Hull J, El Hindy M, Taylor SC, El Amraoui F, PatonThomas C, White P, Williams H, Haynes H, Bertoni A, Radlwimmer B (2016) Decreased expression of the mitochondrial BCAT protein correlates with improved patient survival in IDHWT gliomas. Brain Pathol 26(6):789-791. https://doi.org/10. 1111/bpa.12385

Dey P, Baddour J, Muller F, Wu CC, Wang H, Liao WT, Lan Z, Chen A, Gutschner T, Kang Y, Fleming J (2017) Genomic deletion of malic enzyme 2 confers collateral lethality in pancreatic cancer. Nature 542(7639):119-123. https://doi.org/10.1038/natur e21052

Eagle, H. (1955). Nutrition needs of mammalian cells in tissue culture. Science 122(3168):501-504. https://www.jstor.org/stable/17510 11

Fadaka A, Ajiboye B, Ojo O, Adewale O, Olayide I, Emuowhochere R (2017) Biology of glucose metabolization in cancer cells. J Oncol Sci 3(2):45-51. https://doi.org/10.1016/j.jons.2017.06.002

Furusawa A, Miyamoto M, Takano M, Tsuda H, Song YS, Aoki D, Miyasaka N, Inazawa J, Inoue J (2018) Ovarian cancer therapeutic potential of glutamine depletion based on GS expression. Carcinogenesis 39(6):758-766. https://doi.org/10.1093/carcin/bgy033

Glazer ES, Piccirillo M, Albino V, Di Giacomo R, Palaia R, Mastro AA, Beneduce G, Castello G, De Rosa V, Petrillo A, Ascierto PA (2010) Phase II study of pegylated arginine deiminase for nonresectable and metastatic hepatocellular carcinoma. J Clin Oncol 28(13):2220-2226. https://doi.org/10.1200/JCO.2009.26.7765

Goto M, Miyahara I, Hirotsu K, Conway M, Yennawar N, Islam MM, Hutson SM (2005) Structural determinants for branched-chain aminotransferase isozyme-specific inhibition by the anticonvulsant drug gabapentin. J Biol Chem 280(44):37246-37256. https:// doi.org/10.1074/jbc.M506486200

Grankvist N, Lagerborg KA, Jain M, Nilsson R (2018) Gabapentin can suppress cell proliferation independent of the cytosolic branched-chain amino acid transferase 1 (BCAT1). Biochemistry 57(49):6762-6766. https://doi.org/10.1021/acs.biochem.8b01031

Grasmann G, Smolle E, Olschewski H, Leithner K (2019) Gluconeogenesis in cancer cells-repurposing of a starvation-induced metabolic pathway? Biochim Biophys Acta 1872(1):24-36. https://doi.org/10.1016/j.bbcan.2019.05.006

Gross MI, Demo SD, Dennison JB, Chen L, Chernov-Rogan T, Goyal B, Janes JR, Laidig GJ, Lewis ER, Li J, MacKinnon AL (2014) Antitumor activity of the glutaminase inhibitor CB-839 in triplenegative breast cancer. Mol Cancer Ther 13(4):890-901. https:// doi.org/10.1158/1535-7163.MCT-13-0870

Halpern BC, Clark BR, Hardy DN, Halpern RM, Smith RA (1974) The effect of replacement of methionine by homocystine on survival of malignant and normal adult mammalian cells in culture. Proc Natl Acad Sci 71(4):1133-1136. https://doi.org/10.1073/pnas. 71.4.1133

Han Q, Tan Y, Hoffman RM (2020) Oral dosing of recombinant methioninase is associated with a 70\% drop in PSA in a patient with bone-metastatic prostate cancer and 50\% reduction in circulating methionine in a high-stage ovarian cancer patient. Anticancer Res 40(5):2813-2819

Hattori A, Tsunoda M, Konuma T, Kobayashi M, Nagy T, Glushka J, Tayyari F, McSkimming D, Kannan N, Tojo A, Edison AS (2017) Cancer progression by reprogrammed BCAA metabolism in myeloid leukaemia. Nature 545(7655):500-504. https:// doi.org/10.1038/nature22314

Hensley CT, Wasti AT, DeBerardinis RJ (2013) Glutamine and cancer: cell biology, physiology, and clinical opportunities. J Clin Investig 123(9):3678-3684. https://doi.org/10.1172/JCI69600

Hodakoski C, Hopkins BD, Zhang G, Su T, Cheng Z, Morris R, Rhee KY, Goncalves MD, Cantley LC (2019) Rac-mediated macropinocytosis of extracellular protein promotes glucose independence in non-small cell lung cancer. Cancers 11(1):37. https://doi.org/10.3390/cancers11010037

Hoffman RM (2015) Development of recombinant methioninase to target the general cancer-specific metabolic defect of methionine dependence: a 40-year odyssey. Expert Opin Biol Ther 15(1):21-31. https://doi.org/10.1517/14712598.2015.963050

Hoffman RM, Erbe RW (1976) High in vivo rates of methionine biosynthesis in transformed human and malignant rat cells auxotrophic for methionine. Proc Natl Acad Sci 73(5):1523-1527. https://doi.org/10.1073/pnas.73.5.1523

Hoffman RM, Jacobsen SJ (1980) Reversible growth arrest in simian virus 40-transformed human fibroblasts. Proc Natl Acad Sci 77(12):7306-7310. https://doi.org/10.1073/pnas.77.12.7306

Hoffman RM, Jacobsen SJ, Erbe RW (1979) Reversion to methionine independence in simian virus 40-transformed human and malignant rat fibroblasts is associated with altered ploidy and altered properties of transformation. Proc Natl Acad Sci 76(3):13131317. https://doi.org/10.1073/pnas.76.3.1313

Hosios AM, Hecht VC, Danai LV, Johnson MO, Rathmell JC, Steinhauser ML, Manalis SR, Vander Heiden MG (2016) Amino acids rather than glucose account for the majority of cell mass in proliferating mammalian cells. Dev Cell 36(5):540-549. https:// doi.org/10.1016/j.devcel.2016.02.012

Hsu PP, Sabatini DM (2008) Cancer cell metabolism: Warburg and beyond. Cell 134(5):703-707. https://doi.org/10.1016/j.cell. 2008.08.021

Jain M, Nilsson R, Sharma S, Madhusudhan N, Kitami T, Souza AL, Kafri R, Kirschner MW, Clish CB, Mootha VK (2012) Metabolite profiling identifies a key role for glycine in rapid cancer cell proliferation. Science 336(6084):1040-1044. https://doi.org/10. 1126/science. 1218595

Jeon H, Kim JH, Lee E, Jang YJ, Son JE, Kwon JY, Lim TG, Kim S, Park JHY, Kim JE, Lee KW (2016) Methionine deprivation suppresses triple-negative breast cancer metastasis in vitro and in vivo. Oncotarget 7(41):67223-67234

Kaiser P (2020) Methionine dependence of cancer. Biomolecules 10(4):568. https://doi.org/10.3390/biom10040568 
Kawaguchi K, Han Q, Li S, Tan Y, Igarashi K, Miyake K, Kiyuna T, Miyake M, Chemielwski B, Nelson SD, Russell TA (2018) Intra-tumor L-methionine level highly correlates with tumor size in both pancreatic cancer and melanoma patient-derived orthotopic xenograft (PDOX) nude-mouse models. Oncotarget 9(13):11119-11125

Kelly MP, Jungbluth AA, Wu BW, Bomalaski J, Old LJ, Ritter G (2012) Arginine deiminase PEG20 inhibits growth of small cell lung cancers lacking expression of argininosuccinate synthetase. Br J Cancer 106(2):324-332. https://doi.org/10.1038/bjc.2011. 524

Kim JW, Dang CV (2006) Cancer's molecular sweet tooth and the Warburg effect. Can Res 66(18):8927-8930. https://doi.org/10. 1158/0008-5472.CAN-06-1501

Klement RJ (2017) Beneficial effects of ketogenic diets for cancer patients: a realist review with focus on evidence and confirmation. Med Oncol 34(8):132. https://doi.org/10.1007/ s12032-017-0991-5

Komninou D, Leutzinger Y, Reddy BS, Richie JP Jr (2006) Methionine restriction inhibits colon carcinogenesis. Nutr Cancer 54(2):202_ 208. https://doi.org/10.1207/s15327914nc5402_6

Kreis, W., Hession, C. (1973). Biological effects of enzymatic deprivation of L-methionine in cell culture and an experimental tumor. Cancer research, 33(8):1866-1869. https://cancerres.aacrjourna 1s.org/content/canres/33/8/1866.full.pdf

Kukkar A, Bali A, Singh N, Jaggi AS (2013) Implications and mechanism of action of gabapentin in neuropathic pain. Arch Pharmacal Res 36(3):237-251. https://doi.org/10.1007/s12272-013-0057-y

Le A, Lane AN, Hamaker M, Bose S, Gouw A, Barbi J, Tsukamoto T, Rojas CJ, Slusher BS, Zhang H, Zimmerman LJ (2012) Glucoseindependent glutamine metabolism via TCA cycling for proliferation and survival in B cells. Cell Metab 15(1):110-121. https:// doi.org/10.1016/j.cmet.2011.12.009

Li Z, Zhang H (2016) Reprogramming of glucose, fatty acid and amino acid metabolism for cancer progression. Cell Mol Life Sci 73(2):377-392. https://doi.org/10.1007/s00018-015-2070-4

Li XB, Gu JD, Zhou QH (2015) Review of aerobic glycolysis and its key enzymes-new targets for lung cancer therapy. Thoracic Cancer 6(1):17-24. https://doi.org/10.1111/1759-7714.12148

Llovet JM, Ricci S, Mazzaferro V, Hilgard P, Gane E, Blanc JF, De Oliveira AC, Santoro A, Raoul JL, Forner A, Schwartz M (2008) Sorafenib in advanced hepatocellular carcinoma. N Engl J Med 359(4):378-390. https://doi.org/10.1056/NEJMoa0708857

Lukey MJ, Wilson KF, Cerione RA (2013) Therapeutic strategies impacting cancer cell glutamine metabolism. Future Med Chem 5(14):1685-1700. https://doi.org/10.4155/fmc.13.130

Martinez-Outschoorn UE, Peiris-Pages M, Pestell RG, Sotgia F, Lisanti MP (2017) Cancer metabolism: a therapeutic perspective. Nat Rev Clin Oncol 14(1):11-31. https://doi.org/10.1038/nrclinonc. 2016.60

Mayers JR, Torrence ME, Danai LV, Papagiannakopoulos T, Davidson SM, Bauer MR, Lau AN, Ji BW, Dixit PD, Hosios AM, Muir A (2016) Tissue of origin dictates branched-chain amino acid metabolism in mutant Kras-driven cancers. Science 353(6304):11611165. https://doi.org/10.1126/science.aaf5171

Mecham JO, Rowitch D, Wallace CD, Stern PH, Hoffman RM (1983) The metabolic defect of methionine dependence occurs frequently in human tumor cell lines. Biochem Biophys Res Commun 117(2):429-434. https://doi.org/10.1016/0006-291X(83)91218-4

Meric-Bernstam F, Tannir NM, Mier JW, DeMichele A, Telli ML, Fan AC, Munster PN, Carvajal RD, Orford KW, Bennett MK, Iliopoulos O, Owonikoko TK, Patel MR, McKay R, Infante JR, Voss MH, Iliopoulos O (2016) Phase 1 study of CB-839, a small molecule inhibitor of glutaminase (GLS), alone and in combination with everolimus (E) in patients (pts) with renal cell cancer
(RCC). J Clin Oncol 34(suppl. 15):4568. https://doi.org/10.1200/ JCO.2016.34.15_suppl.4568

Miraki-Moud F, Ghazaly E, Ariza-McNaughton L, Hodby KA, Clear A, Anjos-Afonso F, Liapis K, Grantham M, Sohrabi F, Cavenagh J, Bomalaski JS (2015) Arginine deprivation using pegylated arginine deiminase has activity against primary acute myeloid leukemia cells in vivo. Blood 125(26):4060-4068. https://doi.org/ 10.1182/blood-2014-10-608133

Motzer RJ, Lee CH, Emamekhoo H, Matrana M, Percent I, Hsieh JJ, Hussain A, Vaishampayan UN, Graham R, Liu S, McCune S (2019) LBA54 ENTRATA: randomized, double-blind, phase II study of telaglenastat (tela; CB-839)+ everolimus (E) vs placebo (pbo)+ E in patients (pts) with advanced/metastatic renal cell carcinoma (mRCC). Ann Oncol. https://doi.org/10.1093/annonc/ mdz394.048

National Institute of Health (2017) ENTRATA: CB-839 with Everolimus vs. placebo with Everolimus in patients with RCC (ENTRATA) . Available from https://clinicaltrials.gov/ct2/show/ NCT03163667. Accessed 22 August 2020

Patil MD, Bhaumik J, Babykutty S, Banerjee UC, Fukumura D (2016) Arginine dependence of tumor cells: targeting a chink in cancer's armor. Oncogene 35(38):4957-4972. https://doi.org/ 10.1038/onc. 2016.37

Pavlova NN, Thompson CB (2016) The emerging hallmarks of cancer metabolism. Cell Metab 23(1):27-47. https://doi.org/10. 1016/j.cmet.2015.12.006

Poff AM, Ari C, Seyfried TN, D'Agostino DP (2013) The ketogenic diet and hyperbaric oxygen therapy prolong survival in mice with systemic metastatic cancer. PLoS ONE 8(6):e65522. https://doi.org/10.1371/journal.pone.0065522

Rieger J, Bähr O, Maurer GD, Hattingen E, Franz K, Brucker D, Walenta S, Kämmerer U, Coy JF, Weller M, Steinbach JP (2014) ERGO: A pilot study of ketogenic diet in recurrent glioblastoma Erratum in/ijo/45/6/2605. Int J Oncol 44(6):1843-1852. https:// doi.org/10.3892/ijo.2014.2382

Rocha CM, Barros AS, Goodfellow BJ, Carreira IM, Gomes A, Sousa V, Bernardo J, Carvalho L, Gil AM, Duarte IF (2015) NMR metabolomics of human lung tumours reveals distinct metabolic signatures for adenocarcinoma and squamous cell carcinoma. Carcinogenesis 36(1):68-75. https://doi.org/10. 1093/carcin/bgu226

Stern PH, Hoffman RM (1984) Elevated overall rates of transmethylation in cell lines from diverse human tumors. Vitro 20(8):663670. https://doi.org/10.1007/BF02619617

Stern PH, Wallace CD, Hoffman RM (1984) Altered methionine metabolism occurs in all members of a set of diverse human tumor cell lines. J Cell Physiol 119(1):29-34. https://doi.org/10.1002/ jcp.1041190106

Tan Y, Zavala J Sr, Xu M, Zavala J Jr, Hoffman RM (1996) Serum methionine depletion without side effects by methioninase in metastatic breast cancer patients. Anticancer Res 16(6C):3937 (PMID: 9042316)

Tardito S, Oudin A, Ahmed SU, Fack F, Keunen O, Zheng L, Miletic H, Sakariassen PØ, Weinstock A, Wagner A, Lindsay SL (2015) Glutamine synthetase activity fuels nucleotide biosynthesis and supports growth of glutamine-restricted glioblastoma. Nat Cell Biol 17(12):1556-1568. https://doi.org/10.1038/ncb3272

Tönjes M, Barbus S, Park YJ, Wang W, Schlotter M, Lindroth AM, Pleier SV, Bai AH, Karra D, Piro RM, Felsberg J (2013) BCAT1 promotes cell proliferation through amino acid catabolism in gliomas carrying wild-type IDH1. Nat Med 19(7):901-908. https:// doi.org/10.1038/nm.3217

Urasaki Y, Heath L, Xu CW (2012) Coupling of glucose deprivation with impaired histone H2B monoubiquitination in tumors. PLoS ONE 7(5):e36775. https://doi.org/10.1371/journal.pone.0036775 
Van Den Heuvel APJ, Jing J, Wooster RF, Bachman KE (2012) Analysis of glutamine dependency in non-small cell lung cancer: GLS1 splice variant GAC is essential for cancer cell growth. Cancer Biol Ther 13(12):1185-1194. https://doi.org/10.4161/cbt.21348

Vander Heiden MG, Cantley LC, Thompson CB (2009) Understanding the Warburg effect: the metabolic requirements of cell proliferation. Science 324(5930):1029-1033. https://doi.org/10.1126/scien ce. 1160809

Vettore L, Westbrook RL, Tennant DA (2019) New aspects of amino acid metabolism in cancer. Br J Cancer 122(2):150-156. https:// doi.org/10.1038/s41416-019-0620-5

Vogl DT, Younes A, Stewart K, Orford KW, Bennett M, Siegel D, Berdeja JG (2015) Phase 1 study of CB-839, a first-in-class, glutaminase inhibitor in patients with multiple myeloma and lymphoma. Blood 126(23):3059. https://doi.org/10.1182/blood.V126. 23.3059.3059

Warburg O (1956) On the origin of cancer cells. Science 123(3191):309-314. https://doi.org/10.1126/science.123.3191. 309

Weber DD, Aminazdeh-Gohari S, Kofler B (2018) Ketogenic diet in cancer therapy. Aging 10(2):164-165

Yamamoto J, Han Q, Inubushi S, Sugisawa N, Hamada K, Nishino H, Miyake K, Kumamoto T, Matsuyama R, Bouvet M, Endo I, Hoffman RM (2020) Histone methylation status of H3K4me3 and $\mathrm{H} 3 \mathrm{~K}$ 9me3 under methionine restriction is unstable in methionineaddicted cancer cells, but stable in normal cells. Biochem Biophys Res Commun 533(4):1034-1038. https://doi.org/10.1016/j.bbrc. 2020.09 .108
Zarei M, Nezafat N, Rahbar MR, Negahdaripour M, Sabetian S, Morowvat MH, Ghasemi Y (2019) Decreasing the immunogenicity of arginine deiminase enzyme via structure-based computational analysis. J Biomol Struct Dyn 37(2):523-536. https://doi. org/10.1080/07391102.2018.1431151

Zheng YH, Hu WJ, Chen BC, Grahn THM, Zhao YR, Bao HL, Zhu YF, Zhang QY (2016) BCAT 1, a key prognostic predictor of hepatocellular carcinoma, promotes cell proliferation and induces chemoresistance to cisplatin. Liver Int 36(12):1836-1847. https:// doi.org/10.1111/liv.13178

Zhou W, Mukherjee P, Kiebish MA, Markis WT, Mantis JG, Seyfried TN (2007) The calorically restricted ketogenic diet, an effective alternative therapy for malignant brain cancer. Nutr Metab 4(1):5. https://doi.org/10.1186/1743-7075-4-5

Ziebart T, Walenta S, Kunkel M, Reichert TE, Wagner W, MuellerKlieser W (2011) Metabolic and proteomic differentials in head and neck squamous cell carcinomas and normal gingival tissue. J Cancer Res Clin Oncol 137(2):193-199. https://doi.org/10.1007/ s00432-010-0875-y

Publisher's Note Springer Nature remains neutral with regard to jurisdictional claims in published maps and institutional affiliations. 